\title{
Lung cancer in Europe: turning the spotlight on the biggest cancer killer
}

\author{
Marine Faure
}

Affiliation: European Respiratory Society, EU Affairs Dept, Brussels, Belgium.

Correspondence: Marine Faure, European Respiratory Society, EU Affairs Dept, 49-51 Rue de Tréves, 1040 Brussels, Belgium. E-mail: Marine.Fauredersnet.org

@ERSpublications

ERS activities in Europe to tackle the lung cancer epidemic http://ow.ly/Uf1dA

I believe that the future of humanity is in the progress of reason through science

Émile Zola, French writer and journalist (1840-1902)

Humanity has constantly striven for progress. In Europe, this led to major medical breakthroughs during the late 19th and 20th centuries. From the development of vaccines to the discovery of antibiotics, man gradually managed to control devastating diseases such as tuberculosis or smallpox. Unfortunately, these two centuries also showed that progress is not always associated with health improvement. While prevalent diseases were being tackled, rare illnesses such as lung cancer were beginning to spread. 150 years ago, this type of cancer had a very low incidence among the population. In 1878 , it represented only $1 \%$ of all cancer seen at autopsy in the Institute of Pathology of the University of Dresden, in Germany [1]. However, technical advances in cigarette production and mass marketing, which popularised the use of cigarettes, as well as the rise of the industrial revolution, which increased the exposure to harmful substances, led to a lung cancer pandemic in the 20th and 21st centuries.

Today, lung cancer is the biggest cancer killer in Europe, accounting for 20.8\% of all cancer deaths [2]. Nevertheless, recent progress in lung cancer research offers new hopes for the future. These include the development of new treatments, such as targeted and immune therapies, and advances in lung cancer screening. Similarly, the policy measures taken at the European and national levels mean that European citizens are now better protected from the risk factors, such as tobacco smoke, air pollution and asbestos.

As the leading European medical organisation representing lung health, the European Respiratory Society (ERS) is highly committed to leading these advances and tackling the lung cancer burden. On better prevention, the ERS has a long-established Tobacco Control Committee (TCC), which brings medical expertise on tobacco control globally. Among the achievements of this committee is the creation of "Smokehaz", a website providing policy makers with scientific information on the health hazards of smoking. More recently, the TCC created the "Latin-America Working Group", which focuses on tobacco control in Spanish- and Portuguese-speaking countries. On lung cancer treatment and early diagnosis, the Lung Cancer Working Group was formed as part of the ERS in order to promote the exchange of knowledge and networking between medical professionals. The first outcome was the launch of the "Oncology day", held at the ERS International Congress in Amsterdam (the Netherlands), in September 2015. The meeting covered science to practical skills in the field of lung cancer. Specifically, the working group aims to ensure that lung cancer is at the heart of the ERS and a key priority for its members. In order to do this, ERS experts in the field and a group of patients with experience of lung cancer, via the European Lung Foundation (ELF), have been working together on a range of activities and collaborations. This unique partnership will ensure that patients are fully involved in all initiatives.

Received: Sept 082015 | Accepted after revision: Oct 202015

Conflict of interest: Marine Faure is an employee of the European Respiratory Society.

Copyright OERS 2016 
Furthermore, the ERS is keen to work on this issue directly with the European institutions. On June 27, 2015, the ERS European Union (EU) Affairs Dept (Brussels, Belgium) organised a roundtable entitled "Lung cancer in Europe, tackling the biggest cancer killer" (figure 1). Hosted by Philippe Juvin, French Member of the European Parliament and medical doctor, as well as Jean-Paul Sculier, Chief of Service of intensive care, oncology emergency and thoracic oncology at the Institut Jules Bordet in Brussels and ERS EU affairs secretary, the event took place in the European quarter of Brussels and highlighted recent advances and positive perspectives in the battle against lung cancer.

Philippe Juvin, in opening the roundtable, informed participants about existing EU measures to fight lung cancer. These include the Tobacco Products Directive, the legislation package on air pollution and the revised clinical trials regulation, which will help to advance research in this area. He also mentioned what remains to be done at the EU level, such as removing the existing derogations in the asbestos regulation, the potential threat of the new data protection legislation for medical research and the need for the EU to develop guidelines on lung cancer screening.

Dominika Trzaska, Scientific Officer of the Health Directorate of the Research and Innovation Directorate-General of the European Commission, emphasised the role of the EU in supporting lung cancer research. She pointed out that between 2007 and 2015, 39 projects specifically focused on lung cancer were supported by the European Commission, with an overall financial contribution of $€ 44$ million [3]. This appears, however, as a paltry contribution when it is known that the European Commission foresees allocation of $€ 2.7$ billion to nuclear fusion research for 2014-2020 [4].

Mina Gaga, Director and Head of the 7th Respiratory Medicine Dept and Asthma Centre as well as medical doctor at the Athens Chest Hospital (Athens, Greece), represented the first speaker of the scientific panel. She updated the audience with the effective advances in lung cancer screening. She presented the recent ERS and European Society of Radiology joint white paper, which advocates for lung cancer screening performed in comprehensive, quality-assured programmes within a clinical trial or in a routine clinical practice, at certified multidisciplinary medical centres and combined with a strong smoking-cessation programme [5]. These scientific recommendations could serve as a basis for the implementation of EU guidelines on lung cancer screening and diagnosis, as has already been successfully achieved for breast [6], colorectal [7] and cervical [8] cancer. The ERS EU Affairs Dept, in cooperation with Philippe Juvin, is actively working to promote this idea to EU stakeholders.

Jean-Paul Sculier opened the discussion on the future of lung cancer treatment and presented the different options for lung cancer patients, such as chemotherapy and also the recent targeted and immune therapies. He pointed out that these new treatments are very encouraging as they only target the cancer-specific genes or proteins of the patient, or the tissue environment that contributes to cancer growth. However, he reminded the audience that these therapies are still under development and their effectiveness is very dependent on the type of cancer. The contribution of the EU into lung cancer research will be crucial for the full effectiveness of these promising medicines.

On the same topic, Anne-Pascale Meert, Chair of the ERS Thoracic Oncology Assembly and Clinical Director for intensive care, oncology emergency and thoracic oncology at the Institut Jules Bordet in Brussels, gave an overview of the ERS HERMES (Harmonised Education in Respiratory Medicine for European Specialists) initiative. She stressed that one of the project's objectives is to use a multidisciplinary

FIGURE 1 European Respiratory Society roundtable entitled "Lung cancer in Europe, tackling the biggest cancer killer". From left to right: Pierre Blanchard, Dominika Trzaska, Jean-Paul Sculier, Philippe Juvin, Anne-Pascale Meert, Mina Gaga.

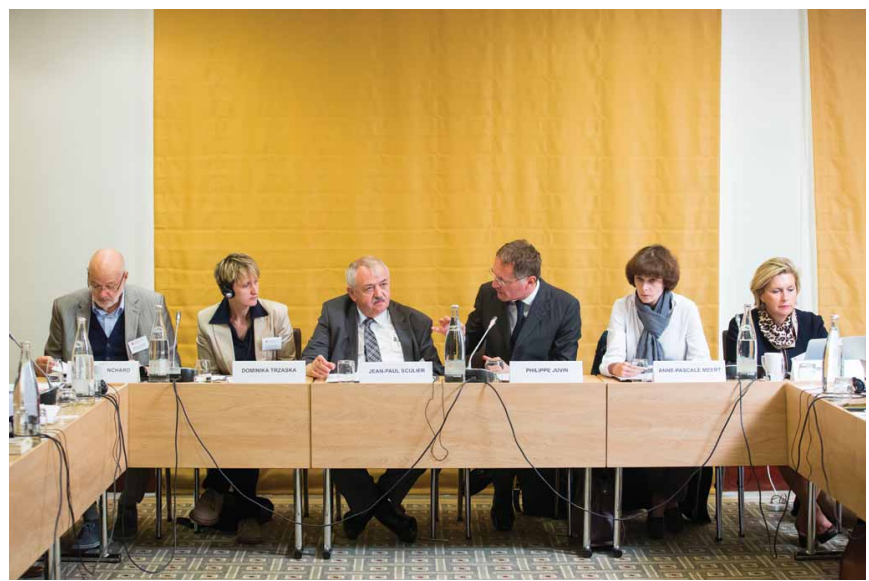


approach by harmonising education of various European specialists involved in thoracic oncology. This would eventually improve the existing inequalities in the provision of lung cancer care in Europe.

Pierre Blanchard, a former European Commission official as well as a lung cancer survivor, gave the patient perspective on lung cancer treatment. Talking about his own experience, Pierre Blanchard suggested that more explanation should be given by health professionals to patients on the adverse effects of their treatment (i.e. surgery, chemotherapy, targeted therapies) and that more psychological support should be provided. ELF, founded by the ERS and focusing on patients, follows the same line by devoting an information page to lung cancer patients on its website. ELF also gives a voice to patients by allowing them to stress their key priorities on lung cancer treatment and management as part of the ERS Lung Cancer Working Group.

This roundtable was a first step towards collaboration between EU policy makers, medical professionals and patients. It showed that crucial actors are willing to work together, at their respective levels, to fight lung cancer. Effective research can only be carried out with strong political support. As a supranational organisation, the EU has a key role to play in increasing its financial support as well as raising awareness of the disease. The event also drew attention to the word "hope", which is too often forgotten in the battle against lung cancer. Instead of recalling the alarming figures, the discussions put the emphasis on the fact that lung cancer could be less prevalent and offer better prognosis to patients in the near future.

The progress of reason through science involves acknowledging past errors and finding the means to rectify them. Despite the lung cancer epidemic exacerbated by man's actions, scientific research has over the years allowed considerable progress in the prevention, diagnosis and treatment of the disease. In the future and through its wide range of activities, the ERS will ensure that the European momentum gathered around this topic is maintained, so that progress benefits human health, and not the reverse.

\section{References}

1 Witschi H. A short history of lung cancer. Toxicol Sci 2001; 64: 4-6.

2 Eurostat Press Office. Causes of death in the EU28 in 2011: 1 in 4 deaths caused by cancer in the EU28. Lung cancer main fatal cancer. Available from http://ec.europa.eu/eurostat/documents/2995521/6131615/3-25112014-BP-EN/ aab2c2d3-aed9-430a-a561-e188b8ef49d8 Date last updated: November 25, 2014. Date last accessed: September 8, 2015.

3 Navarro-Torné A, Vidal M, Trzaska DK, et al. Chronic respiratory diseases and lung cancer research: a perspective from the European Union. Eur Respir J 2015; 46: 1270-1280.

4 EurActiv. EU budget hawks succeed in €960-billion cap. Available from www.euractiv.com/specialreport-budget/ eu-budget-hawks-succeed-cap-960-news-517677 Date last updated: February 11, 2013. Date last accessed: September 8, 2015.

5 Kauczor HU, Bonomo L, Gaga M, et al. ESR/ERS white paper on lung cancer screening. Eur Respir J 2015; 46: 28-39.

6 Perry N, Broeders M, de Wolf C, et al., eds. European guidelines for quality assurance in breast cancer screening and diagnosis. 4th Edn. European Communities, 2006. http://ec.europa.eu/health/ph_projects/2002/cancer/fp_ cancer_2002_ext_guid_01.pdf

7 Segnan N, Patnick J, von Karsa L, eds. European guidelines for quality assurance in colorectal cancer screening and diagnosis. 1st Edn. European Commission, 2010. Available from http://bookshop.europa.eu/is-bin/INTERSHOP. enfinity/WFS/EU-Bookshop-Site/en_GB/-/EUR/ViewPublication-Start?PublicationKey=ND3210390Ｄate last updated: August 23, 2012. Date last accessed: September 8, 2015.

8 Arbyn M, Anttila A, Jordan J, et al., eds. European guidelines for quality assurance in cervical cancer screening. 2nd Edn. European Communities, 2008. http://screening.iarc.fr/doc/ND7007117ENC_002.pdf 